\title{
"É bom a gente aprendê mais, falá melhó": crenças e atitudes linguísticas dos sambadores e sambadeiras de roda do grupo Samba Chula de São Braz
}

\author{
"É bom a gente aprendê mais, falá \\ melhó": the beliefs and the linguistic \\ attitudes of the samba \\ players of the group Samba Chula de \\ São Braz
}

Daisy Cordeiro ${ }^{1}$

Lúcia Maria de Jesus Parcero²

Resumo: Este artigo é uma amostra dos achados de uma dissertação de mestrado em andamento intitulada Sambando na cara da sociedade: a resistência na atitude e nos usos linguísticos no contexto do Samba Chula de São Braz. As crenças e atitudes linguísticas dos falantes influenciam o modo como estes percebem uma língua ou variedade linguística. Com isso, este trabalho objetiva analisar a relação das atitudes linguísticas dos sambadores e das sambadeiras do grupo Samba Chula de São Braz com o ensino da norma padrão da Língua Portuguesa e com a percepção das variedades do português brasileiro. A metodologia empregada é descritiva e segue os pressupostos da Sociolinguística Interacional e da Etnografia da Comunicação (qualitativa e interpretativa). Para isso, foram realizadas entrevistas além de observação dos ensaios do grupo em São Braz, comunidade que fica a cerca de 7 quilômetros do centro de Santo Amaro e é uma das comunidades reconhecidas como quilombo na Bahia. O estudo deste tema é pertinente para identificar como uma atitude positiva sobre determinada variedade linguística caracteriza a afirmação da identidade étnico-racial das sambadeiras e dos sambadores de São Braz, ou seja, como o uso da língua pode marcar seu lugar de resistência na sociedade.

Palavras-chave: Atitudes linguísticas; Ensino de Língua Portuguesa; Identidade.

Abstract: This article is a sample of the findings of an ongoing master's thesis entitled Sambando na cara da sociedade: a resistência na atitude e nos usos linguísticos no contexto do Samba Chula de São Braz. The beliefs and linguistic attitudes of the speakers influence how they perceive a language or linguistic variety. The aim of this work is to analyze the relationship between the linguistic attitudes of the samba players of the group Samba Chula de São Braz with the standard Portuguese language teaching and the perception of the varieties of Brazilian Portuguese. The methodology used is descriptive and follows the assumptions of

\footnotetext{
${ }^{1}$ Mestranda pelo Programa de Pós-Graduação em Estudo de Linguagens (PPGEL) da Universidade do Estado da Bahia (UNEB). E-mail: daisycordeiro@yahoo.com.br

2 Orientadora: Professora da Universidade do Estado da Bahia (UNEB), doutora em Linguística pela Universidade Estadual de Campinas (UNICAMP). E-mail: mparcero@gmail.com
} 
Interactional Sociolinguistics and Ethnography of Communication (qualitative and interpretive). For that, interviews were carried out in addition to observing the group's essays in São Braz, a community that is about 7 kilometers from the center of Santo Amaro and is one of the communities recognized as a quilombo in Bahia. The study of this theme is pertinent to identify how a positive attitude on a certain linguistic variety characterizes the affirmation of the ethnic-racial identity of samba players, that is, how the use of language can mark its place of resistance in society.

Keywords: Linguistic Attitudes; Portuguese language teaching; Identity

\section{Introdução}

Este trabalho tem por objetivo analisar a relação das atitudes linguísticas dos sambadores e das sambadeiras do grupo Samba Chula de São Braz com o ensino da norma padrão da Língua Portuguesa e com a percepção das variedades do português brasileiro. Para sustentação teórica do trabalho e análise dos dados, foram utilizados conceitos da Sociolinguística Interacional, para compreendermos o uso da língua em interação social e da Etnografia da Comunicação, no sentido de analisarmos eventos de fala no contexto social e cultural.

A língua é um fenômeno social e está sujeita, ao curso da história, às mudanças e transformações socioculturais. Língua e cultura são indissociáveis, não se pode trabalhar com uma prescindindo a outra. Com efeito, a língua diz muito sobre o povo que a usa. Está diretamente ligada à identidade dos seus falantes, aos seus modos, seus costumes pois, como explica Moita Lopes (2002, p. 30), "[...] é por meio [do] processo de construção do significado, no qual o interlocutor é crucial, que as pessoas se tornam conscientes de quem são, construindo suas identidades sociais ao agir no mundo por intermédio da linguagem". Por identidade, entendemos "[...] algo formado, ao longo do tempo, através de processos inconscientes, e não algo inato, existente na consciência no momento do nascimento" (HALL, 2005, p. 38). Desse modo, assim como a língua é variável, está em constante transformação, a identidade também está em processo.

De acordo com Parcero (2007, p. 168), "atitudes linguísticas consistem em ideias e julgamentos, a partir dos quais uma língua e seus falantes são avaliados". O ato de falar representa muito mais que transmissão e recepção de códigos. Somos avaliados, admirados ou odiados dependendo da forma como uma língua ou uma variedade linguística é julgada. Esse julgamento está além das questões gramaticais: 0 fator social condiciona as atitudes linguísticas. Com isso, não apenas a língua ou variedade é avaliada, mas também o grupo social que a utiliza.

Justamente pela relação língua, cultura, identidade e sociedade, o ensino da língua materna ou estrangeira não pode ignorar os usos reais da língua, limitando-se a regras gramaticais arcaicas ou a trechos de livros de séculos passados. Uma abordagem sociolinguística de ensino implica integrar às aulas as características socioculturais da localidade da escola, bem como em não ignorar ou menosprezar as particularidades na fala dos estudantes e da sua comunidade. O ensino da Língua Portuguesa na perspectiva da Sociolinguística possibilita que os indivíduos desenvolvam uma atitude linguística positiva sobre a diversidade linguística. Do contrário, uma atitude negativa sobre variedades linguísticas, em especial as variedades estigmatizadas, acarreta na criação de estereótipos e manutenção do preconceito linguístico. 
O estudo deste tema é pertinente para identificar como uma atitude positiva sobre determinada variedade linguística pode caracterizar a afirmação da identidade étnico-racial das sambadeiras e dos sambadores de São Braz, ou seja, como o uso da língua pode marcar seu lugar de resistência na sociedade. Este artigo está estruturado da seguinte forma: fundamentação teórica relacionada aos estudos da Sociolinguística e das atitudes linguísticas, um breve histórico sobre o grupo Samba Chula de São Braz e informações sobre o locus da pesquisa, apresentação da metodologia utilizada, discussão dos resultados da pesquisa e as considerações finais.

\section{Pressupostos teóricos}

A Sociolinguística estuda aspectos da relação língua e sociedade e toma como dados a língua em situações naturais de interação social. A perspectiva sociolinguística se opõe às posições teóricas que consideram a língua isolada de seu contexto social. Assim sendo, a pesquisa sociolinguística se orienta por procedimentos metodológicos adequados ao trabalho de campo escolhido a depender de temas e interesses do pesquisador. O campo, no caso, pode se referir a uma comunidade, que pode ser um local urbano ou rural, e seus contextos sociais específicos de interação verbal, como o contexto familiar, escolar, religioso, etc (CORDEIRO; PARCERO, 2017).

Os estudos sociolinguísticos são classificados em três ondas de análise. Essa categorização, proposta por Eckert, traz em cada onda uma abordagem diferente sobre a variação linguística com distintas metodologias e práticas analíticas. A primeira onda contempla os estudos iniciados por Labov, que envolvem a relação variáveis linguísticas e fatores sociais, como escolaridade, gênero, classe social, etc. A metodologia empregada na primeira onda é quantitativa. A segunda onda é qualitativa e trabalha com uma perspectiva etnográfica. As pesquisas da segunda onda são realizadas em pequenas comunidades nas quais o pesquisador busca correlacionar a variação linguística a práticas sociais da comunidade. Na terceira onda, há também o método quantitativo e tem como objetivo identificar as categorias sociais que atuam nos padrões linguísticos. A presente pesquisa está inserida nos estudos da segunda onda por ser realizada em uma pequena comunidade e ter cunho etnográfico.

Os estudos sociolinguísticos podem trabalhar com uma abordagem macro, com as comunidades de fala, e/ou micro, com as comunidades de prática. A pesquisa com comunidade de fala utiliza coleta padronizada (entrevista sociolinguística) enquanto, com a comunidade de prática, ocorre a coleta etnográfica, com a observação dos participantes. Em uma comunidade de prática, os membros estão engajados em algum empreendimento em comum (FREITAG, 2014).

Entre os campos de estudo da Sociolinguística, temos a Variacionista, a Interacional, a Sociologia da linguagem, a Etnolinguística e a Etnografia da Comunicação. Neste artigo, os pressupostos teóricometodológicos utilizados são na área da Sociolinguística Interacional e da Etnografia da Comunicação.

A Etnografia da Comunicação foi desenvolvida inicialmente por Dell Hymes e tem como fundamentos a linguística e a antropologia. A metodologia empregada é qualitativa e exige interação do pesquisador com a comunidade. Segundo Alkmim (2001, p. 31), a Etnografia da Comunicação "[...] pretende descrever e interpretar o comportamento linguístico no contexto cultural e [...] procura definir as funções da linguagem a partir da observação da fala e das regras sociais próprias a cada comunidade". 
Essa vertente da sociolinguística busca compreender determinada comunidade a partir da observação participante da interação dos membros, dos seus eventos de fala.

Além do contexto, a Etnografia da Comunicação se interessa pela Competência Comunicativa. A Competência Comunicativa, conceptualizada por Hymes nos anos 1970, é a capacidade de mobilizar conhecimentos de língua e de comunicação sob certas atitudes em interação com o propósito de se situar socialmente em uma língua. Desse modo, além de assimilar questões estruturais da língua, o falante deve adquirir Competência Comunicativa.

A Sociolinguística Interacional dedica-se à descrição dos fenômenos de interação humana. Foi apresentada na década de 1970 pelo linguista Gumperz (2002). Estuda, em um grupo social, as estratégias de que o falante lança mão, as pistas de contextualização, e as inferências sobre os conteúdos compartilhados na interação verbal. Os sujeitos detêm papéis sociais, e os processos interativos de que participam constituem a realidade social.

A ação mais estudada neste campo é a conversação e a sua contribuição à comunicação de significados sociais, ou seja, os usos da língua em uma situação de comunicação verbal e as intenções, crenças e atitudes sobre estes usos. Além das regras gramaticais, o indivíduo deve conhecer e seguir as regras culturais. Segundo Goffman (2002, p. 17), "as regras culturais estabelecem como os indivíduos devem se conduzir em virtude de estarem em um agrupamento, e essas regras de convivência, quando seguidas, organizam socialmente o comportamento daqueles presentes à situação". Deste modo, estudam-se também as condutas que acompanham a fala e o conhecimento sociocultural que os sujeitos compartilham. Não se trabalha com hipóteses e sim com questões de partida. Trata-se de uma pesquisa de metodologia qualitativa e interpretativa.

\section{A Sociolinguística e o ensino de língua materna}

O distanciamento entre o que é ensinado nas aulas e o vernáculo, ou seja, a língua de uso dos estudantes, faz com que estes considerem que "Português é muito difícil" (BAGNO, 2015). A razão para a existência desse mito pode ser assim explicada: "Como o nosso ensino de língua sempre se baseou na norma gramatical literária de Portugal, as regras que aprendemos na escola em boa parte não correspondem à língua que realmente falamos e escrevemos no Brasil" (BAGNO, 2015, p. 57). A norma a ser ensinada nas escolas é a culta, a que de fato é usada nas interações sociais de interactantes cultos. A norma padrão segue estática em gramáticas cujos autores negam-se a aceitar as variedades e mudanças linguísticas no Português Brasileiro.

De acordo com Freire (1989), a educação está diretamente ligada à política. Ainda que a educação não seja neutra, o ato de educar não pode ser feito de forma manipuladora, reproduzindo a ideologia dominante. "Do lado dos dominantes, todas as estratégias, essencialmente defensivas, visam conservar a posição ocupada, portanto, perpetuar o status quo, ao manter e fazer durar os princípios que servem de fundamento à dominação" (BOURDIEU, 2006, p. 32). Aplicar os conceitos da Sociolinguística ao ensino da Língua Portuguesa oportuniza que os estudantes tenham conhecimento das variações e mudanças da língua, da sua relação com a sociedade e da sua prática como instrumento de poder (BOURDIEU, 1998). 
O educador precisa ainda ter conhecimento do contexto sociocultural no qual o discente está inserido. Correlacionar temas à realidade do aluno faz com que o discente se identifique com o que é ministrado. Afinal, a escola é local de socialização, onde os alunos trocam experiências, conhecem outros costumes, outros jeitos de falar. Assim, é preciso que o ensino de Língua Portuguesa seja culturalmente sensível:

\begin{abstract}
As formas de implementação dessa pedagogia culturalmente sensível são múltiplas: aproveitar as experiências e vivências que as crianças trazem consigo, repetindo padrões interacionais que thes são familiares; desenvolvendo estratégias que façam a distinção entre eventos de oralidade e de letramento; implementar estratégias de envolvimento, permitindo que a criança fale, ratificando-a como falante legítimo, respeitando-Ihe as peculiaridades, acolhendo-Ihe as sugestões e tópicos, incentivando-a a manifestar-se, fornecendo-lhe modelos de estilos monitorados da língua e mostrandoIhe como e quando usar esses estilos. Enfim, a escola tem de aceitar a diversidade e torná-la funcional. (BORTONI-RICARDO, 2005, p. 209).
\end{abstract}

Com uma atitude positiva, os estudantes tornam-se mais receptivos e motivados com as aulas. Desta forma, os alunos se identificarão e se sentirão representados socialmente. A relevância de uma base teórico-metodológica sociolinguística se fundamenta em proporcionar condições para o desenvolvimento de uma educação linguística, tornando claro que a língua não é estática nem homogênea, e que é preciso combater o preconceito linguístico. De acordo com Botassini (2015, p. 124), "o termo preconceito linguístico refere-se à atitude negativa frente a determinado grupo linguístico sem razão aparente." Como afirma Bourdieu (1998, p. 160-1), "a língua não é somente um instrumento de comunicação ou mesmo de conhecimento, mas um instrumento de poder. Não procuramos somente ser compreendidos, mas também obedecidos, acreditados, respeitados, reconhecidos". O preconceito linguístico menospreza as variantes linguísticas do português, sejam regionais ou sociais. As variantes estigmatizadas são as variantes utilizadas pelas camadas mais baixas da sociedade, portanto, as camadas não prestigiadas. Portanto, há uma grande necessidade de democratizar o ensino escolar, abrindo as portas para as inúmeras variedades linguísticas. A diversidade linguística do aluno deve ser respeitada, mas a norma de prestígio deve ser ensinada para auxiliar na construção da sua cidadania.

\title{
Atitudes linguísticas
}

Assim como indivíduos são socialmente avaliados, as línguas e as variedades linguísticas também são. Essa avaliação não leva em consideração apenas questões morfossintáticas ou fonéticofonológicas, mas fatores socioculturais. De acordo com Rodrigues (2012),

As atitudes linguísticas são atitudes psicossociais, ou seja, se as línguas têm conotações
sociais, é natural que sejam avaliadas (admiradas ou desprezadas) a partir do status ou
das características sociais dos seus usuários. Por isso, a atitude em relação a uma
língua e a atitude em relação ao grupo social que dela se serve parecem confundir-se.
Embora as línguas sejam entidades objetivamente comparáveis, o que frequentemente
provoca as manifestações de apreço ou dasapreço [sic] são as opiniões sobre os grupos
sociais ou etnolinguísticos. O habitual é que sejam os grupos sociais mais prestigiados,
mais poderosos socioeconomicamente, os que ditam as normas das atitudes linguísticas
das comunidades de fala. Por isso, as atitudes costumam ser positivas em relação à 
língua, aos usos e às características dos falantes com maior prestígio e de mais alta posição social. (RODRIGUES, 2012, p. 363-4).

É por meio das atitudes dos falantes que determinada língua ou variedade linguística pode ser estigmatizada ou prestigiada. Além disso, se a atitude linguística for extremamente negativa, pode acontecer a "morte" de uma língua, outrora usada por antepassados e negada pelas gerações mais novas (AGUILERA, 2008). Desse modo, "o estudo das atitudes é importante para a sociolingüística, uma vez que pode 'predizer' um dado comportamento linguístico: a escolha de uma língua particular em comunidade multilingüe, lealdade, língua de prestígio entre outras" (PARCERO, 2007, p. 39). Tem ainda a importância de prever se determinada variação tenderá a mudança, levando-se em conta seu status de prestígio, e também a escolha de aprendizado de uma língua estrangeira, considerando-se que o domínio desse outro idioma poderá proporcionar ascensão social.

Assim como crenças, costumes e valores de determinado grupo social diferenciam-no em relação a outros grupos, a língua pode distinguir um dos demais, estando, então, atrelada à identidade. Da mesma forma que a língua está relacionada à identidade, as atitudes linguísticas também estão ligadas a questões identitárias, como explica Rodrigues (2012):

\begin{abstract}
A atitude em relação a uma língua ou ao seu uso é mais facilmente identificável quando se tem em mente que as línguas não são apenas portadoras de formas e atributos linguísticos determinados, mas que também transmitem, por exemplo, conotações sociais, traços culturais, valores sentimentais e éticos. É possível afirmar que as atitudes linguísticas dizem respeito às próprias línguas e à identidade dos seus falantes. Consequentemente, é lógico pensar que, uma vez que exista um elo entre língua e identidade, a atitude linguística há de se manifestar no comportamento dos indivíduos em relação não apenas a essas línguas, mas também em relação a seus usuários. (RODRIGUES, 2012, p. 363)
\end{abstract}

Pode acontecer de o falante ter uma atitude negativa sobre a sua variante linguística. Segundo Rodrigues, "a língua e o status social estão intimamente ligados no sentido de que o segundo influi diretamente sobre o primeiro. A autoavaliação do status linguístico será baixa, sobretudo se o grupo minoritário fala uma variante desprestigiada da língua em questão." (RODRIGUES, 2012, p. 371). Em uma comunidade estratificada, os que são socioeconomicamente dominantes são positivamente avaliados enquanto os das camadas sociais mais baixas são desvalorizados. Além da segregação social, falantes de comunidades marginalizadas sentem-se inferiorizados devido aos seus usos linguísticos.

\title{
As sambadeiras e os sambadores do grupo Samba Chula de São Braz
}

O samba de roda envolve ritmo, canto, dança com movimentos que vão dos pés até a cabeça das sambadeiras e sambadores, resultando em uma manifestaão singular. Há espontaneidade, mas há toda uma liturgia no samba de roda, no qual, embora não haja regras escritas, todos os participantes sabem como agir, como se expressar. Há ainda como elementos básicos para realização do evento samba de roda, o posicionamento dos participantes em círculo (a roda) e o acompanhamento do canto por instrumentos como o pandeiro, a viola, o prato-e-faca ${ }^{3}$, o atabaque, o cavaquinho, o tamborim, o chocalho

\footnotetext{
${ }^{3}$ Prato de esmalte friccionado na borda por uma faca emitindo um som rítmico, característico do samba de roda.
} 
e o machete. Este último, de origem portuguesa, "[...] é um tipo de viola de dez cordas (dispostas geralmente em cinco duplas de cordas), tal como as violas conhecidas em todo o Brasil como 'violas caipiras'. Possui tamanho menor, e timbre mais agudo e 'brilhante' do que o violão, para efeito de comparação" (NOBRE, 2012, p. 2). Além dos instrumentos, as palmas também acompanham o canto e garantem o ritmo e a animação do samba de roda.

No ano de 2004, o samba de roda foi registrado como Patrimônio Cultural Brasileiro pelo Instituto do Patrimônio Histórico e Artístico Nacional (IPHAN) e em 2005 como Patrimônio Histórico Cultural Imaterial da Humanidade pela Organização das Nações Unidas para a Educação, a Ciência e a Cultura (Unesco). O samba de roda faz parte da vida cultural de diversas cidades da Bahia. Somente no Território de Identidade ${ }^{4}$ (TI) Recôncavo, há 120 grupos de samba de roda cadastrados na Associação dos Sambadores e Sambadeiras do Estado da Bahia (ASSEBA). A sede da ASSEBA fica em Santo Amaro, na Casa do Samba, centro de referência para propagação da manifestação cultural além de promover treinamentos, oficinas e pesquisa.

O samba de roda tem como modalidades o samba chula e o samba corrido, sendo este, muitas vezes, chamado simplesmente de samba de roda ou de samba solto. $\mathrm{O}$ que diferencia uma modalidade da outra é que, no samba chula (também chamado de samba de viola, samba amarrado, samba chulado ou samba santo-amarense), a dança e o canto nunca acontecem ao mesmo tempo enquanto, no samba corrido, eles ocorrem simultaneamente. Além disso, no samba chula, apenas uma pessoa de cada vez samba no meio da roda enquanto, no samba corrido, várias pessoas dançam ao mesmo tempo no meio da roda, além de ter um ritmo mais acelerado (IPHAN, 2006). Segundo a etnomusicóloga Döring (2004):

\begin{abstract}
O samba chula é mais complexo musicalmente do que o samba-de-roda e sua origem e presença parecem se centrar quase que exclusivamente na região de Santo Amaro e em poucos outros lugares do Recôncavo. Ele é um samba de viola no qual a viola é tocada de maneira característica com tonalidades determinadas, afinações das cordas, técnicas e acentos rítmicos. (DÖRING, 2004, p. 85).
\end{abstract}

Sobre o canto, ele pode ser responsorial: um dos sambadores canta sozinho uma estrofe e os demais participantes respondem coletivamente outra estrofe. Essa técnica ocorre apenas no samba corrido. No samba chula, somente um ou dois cantadores (neste último caso, formando a parelha) cantam, sem acompanhamento dos instrumentos, uma quadra com dois a quatro versos, podendo ter outra dupla ou os demais presentes na roda que respondem com poucos versos, o chamado relativo.

O Samba Chula de São Braz, apesar do nome, não toca apenas chula, mas também o samba corrido. Em 1995, o grupo foi oficialmente fundado pelos irmãos Antônio Saturno, Seu Alumínio, e João Saturno, o João do Boi, mas os dois irmãos já cantavam o samba chula há muitos anos no pequeno povoado de Santo Amaro. O único CD do grupo foi gravado em 2009 como conquista do prêmio Pixinguinha, com o título Quando dou minha risada, ha, ha... Segundo Silveira Neto (2017):

\footnotetext{
${ }^{4}$ Classificação proposta pelo Governo do Estado da Bahia que divide o estado em 27 territórios com base no sentimento de pertencimento das comunidades. "O território é conceituado como um espaço físico, geograficamente definido, geralmente contínuo, caracterizado por critérios multidimensionais, tais como o ambiente, a economia, a sociedade, a cultura, a política e as instituições, e uma população com grupos sociais relativamente distintos, que se relacionam interna e externamente por meio de processos específicos, onde se pode distinguir um ou mais elementos que indicam identidade, coesão social, cultural e territorial”. (BAHIA, 2018).
} 
Após a gravação deste disco, os chuleiros de São Braz cruzaram o Atlântico e realizaram shows em importantes eventos internacionais de música. Em 2010, participaram do WOMEX, a maior feira de World Music do mundo, em Copenhague. Um ano depois, aterrissaram em Israel para apresentação no Festival Internacional da Primavera Rishon Le Zion, e nos países Bélgica e Holanda para shows no Festival Europalia Brasil. Em 2012, o grupo realizou sua Turnê Europa na França, passando em cidades como Paris (Cité de la Musique), Marseille e Toulouse. Em 2014, ano do falecimento de Seu Alumínio, o grupo participa da $20^{\text {a }}$ edição do PercPan ao lado do cantor e compositor Márcio Vitor, vocalista do grupo Psirico, e foi destaque no Festival Qatar Brasil 2014, realizado no Parque Mia, na cidade de Doha. (SILVEIRA NETO, 2017, p. 59-60).

Como é possível notar, o que começou de forma amadora e despretensiosa, profissionalizou-se e ganhou o mundo. O grupo levou o seu nome, o samba chula e o nome da pequena comunidade rural para outros espaços. Mesmo tendo a oportunidade de viajar para outros lugares, os integrantes sempre voltam para sua terra e, assim, seguem até hoje, sem abandonarem suas raízes.

Após a morte de Seu Alumínio e um grave mal-entendido intercultural no aeroporto de Doha, que acarretou em um desentendimento com o produtor Fernando de Santana (SILVEIRA NETO, 2017), João do Boi sai do grupo e forma o Samba Chula João do Boi. Atualmente, o cantador do Samba Chula de São Braz é Agnaldo de Oliveira Nascimento.

O grupo é formado por doze integrantes e se reúne quinzenalmente, aos domingos, para ensaiar. O local é o restaurante de Fernando de Santana, o Nando's Mariscos, que fica lotado de apreciadores do samba chula e da deliciosa culinária santo-amarense. $O$ fato de o grupo se reunir periodicamente e engajado a um mesmo propósito constitui uma comunidade de prática. Além disso, pelo fato de os integrantes do grupo morararem em ou frequentarem assiduamente uma pequena vila, as suas características socioculturais e sociolinguísticas tornam-se semelhantes, pois "os membros de comunidades tradicionais tendem a ter comportamentos mais homogêneos e há mais vigilância mútua. Podemos dizer então que, nessas comunidades, há maior pressão normativa favorecendo o consenso e atitudes mais homogêneas." (BORTONI-RICARDO, 2008, p. 123). Ademais, durante os ensaios, os sambadores e as sambadeiras formam um agrupamento, que, por estar organizado socialmente em orientação conjunta, compreende um encontro ou comprometimento de face (GOFFMAN, 2002).

\section{Locus da pesquisa}

O TI Recôncavo é formado pelos municípios Cabaceiras do Paraguaçu, Cachoeira, Castro Alves, Conceição do Almeida, Cruz das Almas, Dom Macedo Costa, Governador Mangabeira, Maragogipe, Muniz Ferreira, Muritiba, Nazaré, Salinas da Margarida, Santo Amaro, Santo Antônio de Jesus, São Felipe, São Félix, Sapeaçu, Saubara e Varzedo. Sobre a sua história, temos:

As terras que abrigam o TI Recôncavo, quando da invasão portuguesa, eram ocupadas por Tupinambás (Kirymuré e Paraguaçu). A história do Recôncavo tem intensa analogia com a formação da identidade da chamada cultura baiana. Com o ciclo da cana-deaçúcar e a escravização bastante acentuada na região, a miscigenação tornou-se marca da população do Recôncavo, que contou ainda com a tradição fumageira como importante elemento do modo de ocupação da área, passando, junto com a cana-deaçúcar, pelas fases de ascensão e declínio, influindo diretamente na dinâmica econômica dentro dos contextos estadual e nacional. (BAHIA, 2016, p. 136). 
Segundo dados do Departamento Intersindical de Estatística e Estudos Socioeconômicos (DIEESE), o Recôncavo é o território com o maior porcentual de pessoas que se declaram pretas na Bahia, totalizando $28,2 \%$, além de $56,8 \%$ que se consideram pardas (em todo o estado da Bahia, o percentual é de $17,0 \%$ para pretos e 59,5\% para pardos). Temos, assim, uma região com população majoritária afrodescendente. "Tamanha predominância negra faz com que o Recôncavo resguarde práticas culturais que são, a um só tempo, uma síntese das experiências das populações africanas no Brasil, e a evidência da enorme criatividade dos seus descendentes" (IPHAN, 2006, p. 28). Possivelmente, muitos dessa população negra que vive hoje no Recôncavo descendem dos negros escravizados que trabalharam nos engenhos instalados na região no período colonial.

São Braz fica a cerca de 7 quilômetros do centro de Santo Amaro e é uma das comunidades quilombolas do Recôncavo. Após receber a certificação em 2009 pela Fundação Cultural Palmares, o povoado passa a ter direito a incentivos como apoio financeiro para a educação e manifestações culturais pelo governo federal como política de reparação.

Pouco se tem de informações oficiais acerca da história da vila São Braz. Segundo Santos (2014), São Braz foi, inicialmente, um engenho, construído entre os séculos XVII e XVIII que, após passar por vários proprietários e sucumbir ao declínio do mercado açucareiro na Bahia, foi abandonado e se tornou quilombo, servindo de moradia para os antigos trabalhadores do engenho e seus descendentes. Há ainda na localidade ruínas da capela dedicada ao santo católico São Braz, onde, conforme registros, houve missas e batismos entre os séculos XIX e XX. De acordo com Santos (2014):

\begin{abstract}
Após o entendimento sobre a sucessão de proprietários do engenho e depois povoado, e as constatações presentes na lista dos moradores do século XVIII, podemos concluir que existindo São Braz desde o século XVII, registrando um número de cem moradores no XVIII e aproximadamente 1085 no XXI, como aponta o recenseamento do IBGE, associado à característica de pouco êxodo entre os moradores, não seria incorreto inferir que houve pouco aumento populacional, considerando pouco mais de três séculos de existência da localidade. Notória também é a grande mobilidade que ocorre na região, isso por ela estar inserida em um contexto de modernização da sociedade, não sendo contemplativas, do ponto de vista financeiro, as atividades manuais que ainda são desenvolvidas no local. Dessa forma, se pouco é o crescimento populacional associado ao êxodo, grande tende a ser a manutenção das tradições culturais muito provavelmente originárias de sua formação. (SANTOS, 2014, p. 34-35).
\end{abstract}

Assim como muito das tradições culturais foi mantido, algumas características do falar dos seus antepassados podem ter se mantido.

\title{
Procedimentos metodológicos
}

Esta pesquisa busca compreender as atitudes linguísticas em relação ao ensino da Língua Portuguesa e às variantes do português brasileiro de membros do grupo Samba Chula de São Braz. Para isso, a metodologia empregada é descritiva e segue os pressupostos da Sociolinguística Interacional e da Etnografia da Comunicação (qualitativa e interpretativa). O critério para a escolha dos informantes da pesquisa foi o fato de serem membros do grupo Samba Chula de São Braz, participando dos ensaios quinzenais. 
Os procedimentos e instrumentos de pesquisa foram os seguintes:

1. Observação dos ensaios do grupo Samba Chula de São Braz;

2. Aplicação de entrevistas semiestruturadas e temáticas (uso de smartphone e bloco de anotações) para coleta de dados;

4. Coleta de dados sobre o grupo;

5. Descrição do contexto da pesquisa, dos informantes e dos dados obtidos.

Para este artigo, selecionamos quatro entrevistas. Com base nas respostas obtidas, segue o perfil dos sujeitos:

Quadro 1: Distribuição dos informantes entrevistados

\begin{tabular}{|c|c|c|c|c|c|}
\hline Informante & Idade & Escolaridade & Gênero & Naturalidade & Atividade no grupo \\
\hline AON & 44 & Ensino médio & Masculino & Santo Amaro & Cantador / Toca pandeiro \\
\hline RNS & 65 & $\begin{array}{c}\text { Ensino } \\
\text { Fundamental }\end{array}$ & Feminino & São Braz & $\begin{array}{r}\text { Dança / Relativo / Toca } \\
\text { prato e faca }\end{array}$ \\
\hline MMPS & 69 & $\begin{array}{c}\text { Ensino } \\
\text { Fundamental }\end{array}$ & Feminino & São Braz & $\begin{array}{r}\text { Dança / Relativo / Toca } \\
\text { prato e faca }\end{array}$ \\
\hline
\end{tabular}

Fonte: Elaborado pela autora (2018).

\section{Resultados e discussão}

Quando o informante está inserido em uma comunidade na qual a maioria compartilha a mesma escolaridade, classe socioeconômica e crenças, torna-se difícil identificar diferenças e realizar avaliações das variedades linguísticas do próprio grupo social. Os entrevistados ZMPS, RNS e MS confirmam essa afirmação, como podemos ver em (1), (2) (3), respectivamente:

(1) Doc. Como a senhora caracteriza a fala do povo de São Braz? A senhora percebe alguma diferença?

Inf. Não [inint] eu não percebo puque eu tombém eu falo a merma coisa deles.

Doc. Entendi.

Inf. Eu acho que num tem é diferença ninhuma.

(2) Doc. Como a senhora caracteriza a fala do povo de São Braz? A senhora percebe alguma diferença?

Inf. Eu não acho diferença nenhuma.

Doc. Nenhuma, né?

Inf. Eu acho a... apesar de ser um interior as pessoas aqui têm um português...

Doc. É?

Inf. [inint] uma ô outra pessoa que dá uma pedradazinha assim, mas... (risos) é de leve (risos). 
(3) Doc. Ahn: como o senhor caracteriza a fala de São Braz? Aqui... as pessoas daqui falam de forma diferente ou...

Inf. Não, fala igual

Doc. Todo mundo?

Inf. Todo mundo (risos)

Doc. Não tem nada de especial?

Inf. Não tem não.

ZMPS é mulher, 69 anos e estudou até o primeiro ano do Ensino Fundamental. É marisqueira, nasceu e mora em São Braz. É católica, trabalhou por um tempo em Salvador, mas nunca morou na capital, levava uma hora e meia para ir voltar do trabalho. Faz parte do grupo Samba Chula de São Braz há sete anos, mas, como afirma, samba desde a infância. Além de sambar, ela canta o relativo e toca o prato e faca. A respeito da diversidade linguística, ZMPS não só percebe sua existência como a considera natural, intrínseca da sociedade:

(4) Doc. Você... a senhora acha que existe um modo de falar correto, bonito ou é tudo a mesma coisa?

Inf. Tem gente que fala bonito, cê tá entendeno?

Doc. Tô.

Inf. Tem gente que fala bonito, tem uns que... mas é assim mermo, ser humano é Doc. É... assim memo, né minha fia?

Além disso, a informante afirma que existe um modo de falar "bonito", consequentemente, há modos "feios" de falar; considera que sua fala é diferente da fala ensinada na escola e demonstra interesse em adquirir acesso à norma padrão:

(5) Doc. E sobre o seu modo de falar, o que a senhora acha?

Inf. Eu falo é assim mesmo... (risos)

Doc. Acha que é bonito, gosta, queria falar de outra forma...?

Inf. É, puque é bom a gente aprendê mais, falá melhó, né?

Doc. E o que é falá melhor?

Inf. [inint] melhó puque tem coisa que a rente fala errado, né? Puque a gente... nós brasilêro, a gente fala muitas... muitas coisas errado. Não fala não? Fala, a gente sente [inint] vê.

ZMPS demonstra ainda ter percepção das diferenças linguísticas entre membros de diferentes classes sociais e do uso da fala pelos dominantes para depreciar, oprimir a classe dominada:

(6) Doc. A senhora acha que pode distinguir uma pessoa rica de uma pessoa pobre só pelo jeito de falar?

Inf. É, puque tem gente... tem gente rico que gosta de... somente ni falá já tá homilhano a gente. E.

Doc. Então a senhora acha que só pela fala...

Inf. Só pela fala... é. Só pela fala [...]

RNS é mulher, 65 anos e cursou até a quarta série do Ensino fundamental em Salvador, durante os seis anos que passou morando na capital. Nasceu e mora em São Braz onde trabalha como pescadora artesal. É católica e entrou no grupo Samba Chula de São Braz no início, em 1995, porém saiu e voltou algumas vezes. É sambadeira, canta o relativo e toca prato e faca. A infoormante acredita que há formas 
corretas e erradas de falar e cita alguns exemplos, mas quando perguntada sobre a fala em São Braz ela afirma que todos(as) "falam bem", tendo assim uma atitude positiva quanto a fala do seu grupo social. Além disso, a informante considera de forma positiva sua fala, embora também deseje ter domínio do português culto:

(7) Doc. A senhora acha que existe um modo de falar mais correto, mais errado?

Inf. Ah é. Algumas pessoas falam mais errado... como é que chama mêmo, laje tem pessoas que fala laixe, foice chama fôça e... entendeno? (risos)

Doc. Entendi. Das pessoas que moram aqui, quem você poderia dizer que fala bem e que fala mal assim?

Inf. Se for falar, é quase todas pesso... todas as pessoas.

Doc. Que falam bem?

Inf. Quem falam bem, é.

Doc. E elas falam o quê, a senhora acha que fala bonito?

Inf. É, tem pessoas que precura se expressá mais, né?

Doc. E sobre o seu modo de falar, o que a senhora acha?

Inf. Ah, eu acho muito legal (risos).

Doc. Tem orgulho?

Inf. Eu procuro pesquisá, eu vejo as pessoa falá e eu vou [inint] tá entendeno?

O participante MS tem 63 anos, gênero masculino, estudou até o segundo ano do primário (Ensino Fundamental), nasceu e mora na comunidade negra de São Braz, onde é pescador. Está no grupo de samba chula desde o início e é o responsável pela tumbadora, instrumento de percussão parecido com o atabaque, sendo este último muito utilizado nas cerimônias de candomblé, nas quais MS está autorizado a tocar para o sagrado. Apesar das muitas viagens com o grupo, nunca morou fora de São Braz e herdou da família todo o conhecimento sobre o samba de roda. MS afirma ter orgulho da própria fala, acredita que há um modo mais correto de falar que outro e admira quem "fala bem":

(8) Doc. Ahn: o senhor acha que existe um modo de falar mais correto ou mais bonito que outro?

Inf. Quem estuda mais, fala melhó, né?

Doc. E o que é falar melhor?

Inf. É ter a língua mais solta, não fala as palavra errada (risos).

Doc. Das pessoas que moram aqui em São Braz, quem o senhor poderia dizer que fala bem?

Inf. $\mathrm{F}$ meu primo.

Doc. F? Por que o senhor acha isso?

Inf. Eu não sei, ele fala bem, exprica as coisa bem, eu acho ele uma pessoa muito sábia nisso aí.

Doc. Entendi. E sobre o seu modo de falar, o que o senhora acha?

Inf. (risos) Acho bem, acho bom, né?

Doc. Acha bom? Tem orgulho?

Inf. Tem orgulho é, ixato.

MS atribui à escolaridade o principal fator para adquirir domínio da norma culta da língua portuguesa e acredita que, para aprender o português, é preciso "pagá caro":

(9) Doc. Ahn: o senhor acha que pode distinguir um rico de um pobre pelo modo de falar?

Inf. Acho.

Doc. Acha? Acha que vai ter o que de diferente?

Inf. $O$ estudo, né?

Doc. $O$ estudo? 
Inf. O rico estuda mais que o pobre.

Doc. Hum: o que é para o senhor saber língua... a língua portuguesa?

Inf. É uma coisa bunita, né?

Doc. É, né?

Inf. Mas só que tem que pagá caro pa podê aprendê, né? (risos)

Doc. Verdade. O senhor acha que o português é uma língua difícil?

Inf. Não, acho bunita.

Doc. Na sua opinião, pessoas que não vão à escola falam errado?

Inf. Falam errado, falam errado.

Doc. É?

Inf. É.

AON é homem, tem 44 anos, católico, estudou o Ensino Médio completo, começou, mas não concluiu o curso superior de Tecnologia da Informação. Diferente das sambadeiras, ele nasceu e mora em Santo Amaro e trabalha em São Francisco do Conde como gerente do sistema de informação. No grupo, há mais de dez anos, AON tem a função de cantador e toca pandeiro. É filho e neto de sambadores, fez parte de alguns grupos de samba e tocou por vinte anos com o cantor e compositor santo-amarense Roberto Mendes. Considera-se um homem público, já se candidatou a vereador de Santo Amaro, mas apesar da votação expressiva que recebeu, não foi eleito. Hoje, ele é primeiro suplente na Câmara de vereadores.

Mesmo como morador de Santo Amaro e trabalhando em São Francisco do Conde, AON não identifica diferenças nos costumes e na fala dos moradores de São Braz:

(10) Doc. E na fala?

Inf. Também não percebo, porque na realidade São Braz nada mais é de que um bairro de Santo Amaro, tão próximo, apesar de ser um distrito, mas é tão próximo.

Para AON, é possível identificar a classe social de uma pessoa apenas pela fala, e essa diferenciação deve-se à escolaridade:

(11) Doc. [...] Você acha que pode distinguir um rico de um pobre pela forma de falar? Inf. Na maioria das vezes, sim. Só não vou generalizar, mas na maioria das vezes sim. Talvez até pela... pela oportunidade de... de... de educação, uma série de coisas.

Indagado sobre os diferentes falares no Brasil e sobre a sua fala, o informante AON respondeu:

(12) Inf. Isso é uma coisa muito peculiar porque cada região tem... é a sua linguagem, seus costumes, não é? Porque tipo assim, se você me perguntar: "cê gosta da linguagem do... do nordestino?" eu vou dizê que gosto. Por eu ser nordestino, eu vou valorizá o que é meu, concorda?

Doc. Claro. E sobre o seu modo de falar, o que você acha?

Inf. Rapaz... você agora me apertou, viu? Sei lá... talvez... porque eu tenho muito cuidado até na questão da fala, né? E procuro valorizar sempre minhas raízes, não fugir, até porque é... o carioca tem seus... seus sotaque.

Doc. Isso.

Inf. O paulista tem seus sotaques, mas eu prefiro... já rodei esse mundo todo aqui, de São Paulo, por diversas vezes, Rio também tal, mas eu prefiro sempre valorizar a minha linguagem, a minha fala. Eu acho que falo bem. 
O informante $\mathrm{AON}$, além de reconhecer a existência da variação diatópica, valoriza a fala do seu grupo social e, com isso, valoriza sua cultura, sua identidade. Do contrário, "ao rejeitar sua identidade linguística, mudando seu modo de falar para sugerir origens sociais ou regionais que na verdade não possui, o falante está revelando uma deslealdade linguística." (BOTASSINI, 2015, p. 122). Desse modo, AON tem uma atitude positiva tanto em relação à sua variedade linguística quanto ao grupo social ao qual pertence. Segundo Bortoni-Ricardo (2004):

Essas crenças sobre a superioridade de uma variedade ou falar sobre os demais é um dos mitos que se arraigaram na cultura brasileira. Toda variedade regional ou falar é, antes de tudo, um instrumento identitário, isto é, um recurso que confere identidade a um grupo social. Ser nordestino, ser mineiro, ser carioca etc. é um motivo de orgulho para quem o é, e a forma de alimentar esse orgulho é usar o linguajar de sua região e praticar seus hábitos culturais. (BORTONIRICARDO, 2004, p. 33).

Contudo, AON afirma que tem "muito cuidado" com a sua fala, o que pode ser entendido como monitoramento linguístico. $\mathrm{O}$ informante percebe que há variedades menos valorizadas que outras e, por isso, se preocupa em adequar seus usos linguísticos à norma culta, adquirindo, assim, maior prestígio social.

Além do informante AON, RNS (13) e MS (14) também têm percepção da variação diatópica.

(13) Inf. É, acho [inint] minha genra era cearense, ela... eu achava que ela falava... a voz dela engraçado. $O$ paulista também, aquele sotaque...

Doc. "Porta, porteira" (/p' כr.tə//por.t' ej.rə/)

Inf. É! (risos)

Doc. Acha engraçado?

Inf. Engraçado, é.

(14) Doc. O senhor já teve oportunidade de perceber diferentes tipos de falas entre pessoas de outro estado?

Inf. Mais ô meno.

Doc. Por exemplo, quando o senhor foi para o Rio de Janeiro, São Paulo...

Inf. O sutaque lá é diferente do daqui.

Doc. É?

Inf. $O$ sutaque.

Doc. Mas dá para entender a pessoa?

Inf. Exato, é.

Doc. A língua é a mesma, mas com algumas...

Inf. Diferença.

É possível notar, nas respostas dos sujeitos, a valorização da educação formal como meio de aquisição de segurança linguística. Ainda que sejam integrantes de uma comunidade de prática em uma região de poucos alfabetizados e as principais fontes de renda dos moradores venham da pesca, mariscagem, produção de palitos de bambu para churrasco e da agricultura, fica evidente a valorização do letramento. 


\section{Considerações finais}

Neste artigo, tivemos como objetivo analisar a relação das atitudes linguísticas dos sambadores e das sambadeiras de roda do grupo Samba Chula de São Braz com o ensino da norma padrão da Língua Portuguesa e com a percepção das variedades do português brasileiro.

Ao analisarmos as falas dos informantes, verificamos que estes têm percepção das variedades linguísticas, têm orgulho do seu modo de falar, mas gostariam de "aprendê" mais para "falá melhó", ou seja, falar de acordo com a variedade de prestígio. Para atingir esse objetivo, acreditam que é preciso "pesquisá", estudar mais. Ainda que sua identidade seja valorizada, há a crença que existe uma forma de falar mais "bonita", mais aceita socialmente, cuja obtenção é garantida mediante o ensino formal, na escola. Por isso, o ensino da norma culta deve ser democratizado, já que é objeto de desejo daqueles que não a aprenderam e instrumento de poder do restrito grupo que a domina. Almejar adquirir maior conhecimento formal pode significar desejar se afastar dos trabalhos forçados, dos castigos e da dor, visto que a vila São Braz é uma comunidade remanescente de quilombo, e a maneira de escapar dessa herança seria por meio da educação.

Ademais, identificar no discurso das sambadeiras e sambadores de São Braz atitudes positivas sobre a própria variedade linguística comprova a afirmação da identidade étnico-racial, ou seja, como o uso da língua pode marcar seu lugar de resistência na sociedade. Desse modo, este trabalho é uma contribuição para aprimorar os estudos sobre as atitudes linguísticas, o ensino aliado à Sociolinguística e sobre a identidade social dos falantes.

\section{Referências}

AGUILERA, V. de A. Crenças e atitudes linguísticas: o que dizem os falantes das capitais brasileiras. Estudos linguísticos. São Paulo, n. 37, v. 2, p. 105-112, maio/ago. 2008. Disponível em: <http://www.gel.org.br/estudoslinguisticos/volumes/37/EL_V37N2_11.pdf>. Acesso em 28 de ago. 2018.

ALKMIM, T. M. Sociolinguística: $1^{\text {a }}$ parte. In. MUSSALIM, F.; BENTES, A. C. (Orgs,). Introdução à linguística: domínios e fronteiras. São Paulo: Cortez Editora, 2001. v. 1. p. 21-47.

BAGNO, M. Preconceito linguístico. 56. ed. São Paulo: Parábola Editorial, 2015.

BAHIA. Secretaria de Planejamento. Territórios de Identidade. Disponível em: <http ://www.seplan.ba.gov.br/modules/conteudo/conteudo.php?conteudo=17>. Acesso em 28 ago. 2018.

BAHIA. Superintendência de Estudos Econômicos e Sociais da Bahia. Perfil dos Territórios de Identidade. Salvador: SEI, 2016. v. 2. Disponível em: <http://www.sei.ba.gov.br/index .php?option=com_content\&view=article\&id=2289\&Itemid=265>. Acesso em 26 ago. 2018.

BORTONI-RICARDO, S. M. Educação em língua materna: a sociolinguística na sala de aula. São Paulo: Parábola, 2004.

BORTONI-RICARDO, S. M. Nós chegemu na escola, e agora? Sociolinguística e educação. São Paulo: Parábola Editorial, 2005.

BORTONI-RICARDO, S. M. O professor pesquisador: introdução à pesquisa qualitativa. São Paulo: Parábola Editorial, 2008.

BOTASSINI, J. O. M. A Importância dos Estudos de Crenças e Atitudes para a Sociolinguística. SIGNUM: Estudos da Linguagem, Londrina, n. 18/1, p. 102-131, jun. 2015. Disponível em: <www.uel.br/revistas/uel/index.php/signum/article/download/20327/16552>. Acesso em 07 ago. 2018.

BOURDIEU, P. A produção da crença: contribuição para uma economia dos bens simbólicos. In: BOURDIEU, P. $A$ produção da crença: contribuição para uma economia dos bens simbólicos. Tradução de Guilherme João de Freitas Teixeira e Maria da Graça Jacinto Setton. 3. ed. Porto Alegre: Zouk, 2006. p. 17-111.

BOURDIEU, P. Economia das trocas linguísticas. In: ORTIZ, R. (Org.). Sociologia. São Paulo: Ática, 1998, p. 156 $-183$. 
CORDEIRO, D.; PARCERO, L. M. de J. Sambando na cara da sociedade: a resistência na atitude e nos usos linguísticos no contexto do Samba Chula de São Braz. Anais do XXI Congresso Nacional de Linguística e Filologia: Cadernos do CNLF. v. 21, n. 3. Rio de Janeiro: CIFEFIL, 2017. p. 2302-2314. Disponível em: <http://www.filologia.org.br/xxi_cnlf/cnlf/tomo2/0170.pdf>. Acesso em 13 ago. 2018.

DIEESE. Educação Profissional da Bahia e Territórios de Identidade. Salvador: DIEESE, 2014. v. 2. Disponível em: <https://www.dieese.org.br/anuario/2014/anuarioEducacao ProfissioanalBahiaTerritoriosIdentidade.pdf>. Acesso em 26 mar. 2018.

DÖRING, K. O samba da Bahia: Tradição pouca conhecida. ICTUS. Salvador: PPGMUS/UFBA. v. 5. p. 69-92, 2004. Disponível em: <http://www.ictus.ufba.br/index.php/ictus/article/viewFile/52/95>. Acesso em 28 ago. 2018.

FREIRE, P. A importância do ato de ler: em três artigos que se completam. 23. ed. São Paulo: Cortez, 1989.

FREITAG, R. M. K. Covariação de uma comunidade de práticas. In: LOPES, N. da S.; RAMOS, J.; OLIVEIRA, J. M. de. (orgs.). Diferentes olhares sobre o português brasileiro. Feira de Santana: Editora UEFS, 2014, p. 13-30.

GOFFMAN, E. A situação negligenciada. In: Ribeiro, T; Garcez, P. (orgs.). Sociolinguística Interacional. São Paulo: Loyola, 2002, p. $13-20$.

GUMPERZ, J. J. Convenções de contextualização. In: RIBEIRO, B. T.; GARCEZ, P. M. (orgs.). Sociolinguística Interacional. São Paulo: Loyola, 2002, p. 149-182.

HALL, S. A identidade cultural na pós-modernidade. 10. ed. Rio de Janeiro: DP\&A, 2005.

IPHAN. Samba de Roda do Recôncavo Baiano. Dossiê IPHAN 4: Ministério da Cultura, 2006.

MOITA LOPES, L. P. da. Identidades fragmentadas: a construção discursiva de raça, gênero e sexualidade em sala de aula. Campinas: Mercado de Letras, 2002.

NOBRE, C. Samba de viola machete: Considerações sobre tradição e transformação no Samba de Roda do Recôncavo Baiano. In: MOURA, C. A. (Org.). Diversidade Cultural Afro Brasileira: Ensaios e Reflexões. Brasília: Fundação Palmares, $2012 . \quad$ Disponível em: <https://www.academia.edu/29792407/Samba_de_viola_machete_Considera\%C3\%A7\%C3\%B5es_sobre_tradi \%C3\%A7\%C3\%A3o_e_transforma\%C3\%A7\%C3\%A3o_no_Samba_de_Roda_do_Rec\%C3\%B4ncavo_Baiano>. Acesso em 28 ago. 2018.

PARCERO, L. M. de J. Fazenda Maracujá: sua gente, sua língua, suas crenças. 2007. 191 f. Tese (Doutorado em Linguística) - Universidade Estadual de Campinas. Instituto de Estudos da Linguagem, Campinas, 2007.

PESSOA DE CASTRO, Y. Falares africanos na Bahia: um vocabulário afro-brasileiro. Rio de Janeiro: Academia Brasileira de Letras/ Topbooks Editora, 2001.

RODRIGUES, L. C. B. Atitude, Imaginário, Representação e Identidade Linguística: Aspectos Conceituais. Anais do XVI Congresso Nacional de Linguística e Filologia: Cadernos do CNLF. v. 16. Rio de Janeiro: CIFEFIL, 2012. p. 362-372.

SANTOS, A. de A. Ancestralidade e história no Recôncavo Baiano: construção do conhecimento ancestral no povoado de São Braz, em Santo Amaro. 2014. 130 f. Dissertação (Mestrado em Educação) - Universidade do Estado da Bahia, Salvador, 2014.

SILVEIRA NETO, A. Políticas públicas para as culturas populares e processos de profissionalização. 2017. 110f. Dissertação (Mestrado em Memória Social) - Universidade Federal do Estado do Rio de Janeiro, Rio de Janeiro, 2017. 